http://dx.doi.org/10.1590/0102-311XCO030814

Mauricio L. Barreto

Instituto de Saúde Coletiva Universidade Federal da Bahia, Salvador, Brasil. mauricio@ufba.br

\section{Scientific research and graduate studies at the crossroads in Brazil}

Brazil's scientific production has grown substantially in recent years, when measured by the number of publications in indexed scientific journals. The country ranks 13th in the world in the average number of scientific articles published annually by its researchers 1 . This continuous growth above the world average means that within a few years, Brazilian research will occupy an even more outstanding position. This fact has called attention to Brazil and its scientific community within the international scientific scenario. The trend reflects an active scientific community that reacts to the stimuli created to increase the country's research production. However, when the focus shifts to more applied areas such as patent applications, the situation changes completely. Growth in patent applications has been quite modest, at levels far below overall growth in scientific production. This contradiction has proved to be a constant nightmare for Brazil's science and technology administrators, who have issued challenges in recent years to turn this situation around. The aim is for Brazil to produce not only high quality scientific articles, but also technologies and innovations.

Guimarães is a keen observer and has frequently been an active participant in events related to S\&T (especially in health) in Brazil. He has launched an instigating article that seeks to identify causes and solutions to the factors blocking long-needed changes in the country's S\&T system. He picks up on a hypothesis raised by Durham several years ago, but never sufficiently developed by her or others. He analyzes the peculiarities of one component in Brazil's S\&T system, namely the graduate studies subsystem and its relationship to scientific research. According to the hypothesis, the country's system places research in a subordinate position to graduate studies, while Guimarães defends the need to reverse the direction in this equation, i.e., research as the determinant and leading factor in graduate studies.

Brazil has a reasonably well-consolidated graduate studies program, especially considering the multitudinous chronic structural and organizational problems in the universities. Although the model for the graduate studies system was imposed on the country during the military dictatorship, the system has nevertheless managed to out-perform the universities of which it is a part. To guarantee quality and stimulate the 
graduate studies system, for decades Capes has conducted a continuous process of complex and rigorous evaluation, gaining strength and credibility both inside and outside of academic circles.

The hypothesis presented by Guimarães is highly relevant to this crucial moment in which Brazil's needs substantial changes in its S\&T system, especially S\&T in health. Given the importance of this hypothesis, it should also be discussed exhaustively, since its acceptance needs to be preceded by accumulated evidence and arguments to prove it convincingly to the various stakeholders in graduate studies and research. Properly convincing the stakeholders would lead to the recommendation, development, and implementation of important changes in Brazil's S\&T, especially in the graduate studies component. I agree with Guimarães that rapid changes are necessary in the country's S\&T system, and his proposal to reverse directions in the graduate studies-research equation is one essential measure for effecting such changes. While I see the pertinence of the adjustments proposed by Guimarães, I wish to add to the discussion by proposing a series of other measures that could potentially and effectively change the course of events:

1) The traditional evaluation by Capes needs a change of focus, becoming an inter-agency process (Capes, CNPq, FINEP, FAPs, etc.) and thus involving the different dimensions in the S\&T process. For decades, Capes has led the graduate studies evaluation model by itself. Evaluation has had a huge impact on the development of graduate studies in Brazil. However, for evaluation to serve as impetus for S\&T as a whole and not only graduate studies, structural changes are needed, with an important shift in the evaluation system's focus and strategies. This might require a new structure with great autonomy and agility and a strong mandate to lead the new evaluation process that would have to be designed. Capes' exclusive leadership in this process would come to a close and would be transferred to an interagency space where graduate studies would lose their centrality (despite their importance), with a shift towards S\&T in general, especially research and innovation;

2) Brazilian society expects the products of S\&T to turn into real benefits (material or immaterial). However, the bibliometric focus with its various indices has become the benchmark for scientific evaluation and the principal strategy for objective measurement of impact. While this approach should be an important component of the evaluation system, abusive reliance on it has generated distortions that need to be identified ${ }^{2,3}$. In the health area, the challenge raised by the 1988 Brazilian Constitution and embodied in the SUS results in huge scientific challenges for a complex set of questions ranging from prevention, diagnosis, cure, and a variety of other health issues to the organization of a macrostructure capable of providing broad and equal access to the health resources needed and demanded by the Brazilian population. The solutions will demand competence and creativity from researchers, who will be expected to provide products that will include (but certainly not be limited to) scientific publications. S\&T follow-up and evaluation will necessarily have to be sensitive to these demands and will have to seek adequate ways of evaluating the outputs;

3) A major portion of Brazil's scientific research takes place in the universities, mostly in the State and Federal ones. This becomes even more critical in the country's more peripheral areas, where non-university research institutes are nearly nonexistent. The recent expansion of the Federal System of Universities and Technological Institutes made the country's university system even more capillary, taking new university campuses to many remote areas. This serves as another element at this crucial juncture for Brazil's S\&T system. These new campuses will shape easily to the existing models, so changes are urgent, since the new campuses may not only modify what already exists in the older universities, but also create new reference models for the newer universities, including the shaping of their future research and graduate studies programs;

4) Finally, the university autonomy recommended by the 1988 Constitution is far from a reality. The centralizing model of the S\&T agencies and the fragility and lack of autonomy in many of the public universities mean that the latter can readily adopt models emanating from the center. Most Brazilian universities lack their own S\&T policies and strategies. Scientific research is the responsibility of individual faculty members or small research groups, with limited institutional accountability. University administrators frequently wait for guidelines from the funding agencies, with no capacity to change the course of events. If Brazil wants an S\&T system that connects to the local and regional contexts and priorities, the existing model is inadequate.

In conclusion, this important debate first and foremost demonstrates the need for changes in one of the key components of the S\&T system, the Master's and $\mathrm{PhD}$ graduate studies system, given its central place in the institutions offering such courses, namely the universities and research institutes. The procedures and solutions for the changes will have to be more radical, but Guimarães signals the need to begin this process 
as soon as possible. Further delays will harm Brazil's S\&T system and prevent it from contributing to the changes so needed for the country's development.

1. Regalado A. Brazilian science riding a gusher. Science 2010; 330:1306-12.

2. Barreto ML. Como avaliar as ciências com uma deficiente ciência da avaliação científica? Cad Saúde Pública 2013; 29:1719-21.

3. Barreto ML. The challenge of assessing the impact of science beyond bibliometrics. Rev Saude Pública $2013 ; 47: 834-7$. 